\section{Use of drugs, alcohol and tobacco by people with schizophrenia: case-control study}

\author{
ROBIN G. MCCREADIE on behalf of the SCOTTISH COMORBIDITY \\ STUDY GROUP
}

\begin{abstract}
Background Specialised services should be developed to help people with schizophrenia and associated substance misuse. The extent of the problem therefore needs to be known.
\end{abstract}

Aims To determine the use of drugs, alcohol and tobacco by people with schizophrenia drawn from rural, suburban and urban settings, and to compare use by general population control subjects.

Method People with schizophrenia $(n=316)$ and general population controls of similar gender distribution, age and postcode area of residence $(n=250)$ were identified in rural, urban and suburban areas of Scotland. Use of drugs and alcohol was assessed by the Schedules for Clinical Assessment in Neuropsychiatry, and use of tobacco by a questionnaire.

Results More patients than controls reported problem use of drugs in the past year (22 (7\%) v. 5 (2\%)) and at some time before then $(50$ (20\%) v. $15(6 \%))$ and problem use of alcohol in the past year (42 (17\%) v. 25 (I0\%)) but not at some time previously (99 (40\%) v. 84 (34\%)). More patients were current smokers (162 (65\%) v. $99(40 \%))$.

Conclusions Problem use of drugs and alcohol by people with schizophrenia is greater than in the general population, but absolute numbers are small. Tobacco use is the greatest problem.

Declaration of interest None. The study was funded by the Chief Scientist Office, Scottish Executive, Edinburgh.
It has been suggested that specialised services should be developed to help people with schizophrenia who have associated substance misuse (Scottish Office, 1997). Before doing so, the extent of the problem needs to be known. The prevalence of substance misuse in people with schizophrenia is not easy to assess. A widely quoted American study (Regier et al, 1990) reported a lifetime prevalence of $47 \%$. Rates in UK studies range from 9 to $36 \%$ (Bernadt \& Murray, 1986; Duke et al, 1994; Menezes et al, 1996; Brown, 1998). Accurate case definition is absent from earlier studies, few have made direct comparisons with the local population and most have taken place in cities. In addition to alcohol and drug misuse, cigarette smoking is common in many people with schizophrenia (Hughes et al, 1986). No previous studies have examined patterns of drug, alcohol and tobacco use in both urban and rural environments, and compared them with patterns of use by members of the general population. Our study has attempted this.

\section{METHOD}

\section{Settings}

The study took place in three sites. Nithsdale in south-west Scotland (population 57000 ) is largely rural; the only town of any size is Dumfries (population 30 000). Part of west Glasgow (population $53000)$ is inner city, with mainly highdensity tenemented and high-rise accommodation. In Aberdeen patients were drawn from five general practices (population 32000 ) that serve roughly equal numbers of owner-occupied and rented houses in suburban settings.

\section{Subjects}

Case finding in Nithsdale uses the 'key informant' method (McCreadie, 1982). Regular censuses identify all current inpatients, day patients and out-patients at
Crichton Royal Hospital, Dumfries and patients supported by community psychiatric nurses. These patients have a consensus clinical ICD-10 diagnosis of schizophrenia (World Health Organization, 1992) and a home address in Nithsdale. In addition, general practitioners (GPs), mental health officers (social workers) and voluntary agencies identify any others known to them. The key informant method was also used to identify patients in west Glasgow and Aberdeen.

As stated above, all patients had a consensus clinical diagnosis of schizophrenia. In addition, patients' records were examined and the Operational Checklist for Psychiatric Disorders (OPCRIT; McGuffin et al, 1991) completed. The OPCRIT-associated computer program was used to generate research ICD-10 and DSM-IV (American Psychiatric Association, 1994) diagnoses.

\section{General population controls}

In Nithsdale and Glasgow, through the use of the Community Health Index (a national database that holds details for all patients registered with a Scottish GP), and in Aberdeen, through scrutiny of patients' lists in the five general practices, a general population control was identified for each patient, matched for gender, age (within 1 year), and postcode area of residence (matched to five characters). Controls were not sought for patients continuously an in-patient for more than 6 months.

\section{Assessment of rates of drug, alcohol and tobacco use}

Research nurses interviewed all patients and controls. Prevalence rates of use of drugs and alcohol in the previous year, and at any time before then, were measured using sections 11 and 12 of the Schedules for Clinical Assessment in Neuropsychiatry (SCAN; World Health Organization, 1994). Subjects were then classified as having no use, harmful use, dependence or problem use (harmful use and/or dependence) on the basis of ICD-10 criteria in the year before the interview, or at any time before then. Current substance use was also assessed in patients through keyworker ratings, using a five-point scale: abstinence; use without impairment; misuse; dependence; and severe dependence (Drake et al, 1989; Menezes et al, 1996). Patients and control subjects completed a questionnaire on smoking recently used in a health 
and lifestyle survey of the general population in south-west Scotland (Waldron et al, 1995).

As a check on patients' and control subjects' reports, every 20th patient and control was asked to give a hair and urine sample, the former to assess use in the past 3 months of amphetamines, metamphetamines, benzodiazepines, methadone, opiates and cocaine, and the latter to assess cannabis use.

\section{Statistical analysis}

For univariate comparisons between cases and controls, chi-squared tests for differences in proportions were used, together with calculation of odds ratios and confidence intervals. Multivariate analysis to determine the independence of factors was based on conditional logistic regression. Differences significant at least at the 5\% level are reported.

\section{Ethical approval}

The study was approved by the relevant local research ethics committees. All patients and controls gave written informed consent.

\section{RESULTS}

Of 446 patients identified there were 179 in Nithsdale (point prevalence: 3.14/1000 general population), 168 in Glasgow (3.17/1000 general population) and 99 in Aberdeen (3.09/1000 general practice population). A total of $136 \quad(76 \%)$ Nithsdale patients, 111 (66\%) Glasgow patients and $69(70 \%)$ Aberdeen patients were interviewed. Demographic and clinical data are shown in Table 1 . Those who were interviewed $(n=316,71 \%)$ did not differ from those not interviewed $(n=130,29 \%)$ in age, gender distribution, duration of illness, deprivation scores (Carstairs \& Morris, 1991) and OPCRIT diagnoses. Matched controls were recruited for 250 (79\%) patients, 114 in Nithsdale, 76 in Glasgow and 60 in Aberdeen. Controls were not sought for 27 patients in long-term hospital care. Despite identifying up to six potential controls per patient, controls could not be recruited for $39(12 \%)$.

More matched than unmatched patients were in the most deprived social categories (6 or 7$),(23 \quad(37 \%)$ v. 42 $(17 \%), \quad \chi^{2}=12.1, \quad$ d.f. $=1, \quad P=0.001$,
$\mathrm{OR}=0.4, \quad 95 \% \quad$ CI $\quad 0.2-0.7) . \quad$ Consequently, only matched patient-control pairs were included in the comparisons between patients and controls. More patients were single $(162 \quad(65 \%) \quad v .60$ $(24 \%), \quad \chi^{2}=84.3, \quad$ d.f. $=1, \quad P<0.001$, $\mathrm{OR}=5.8,95 \%$ CI $3.9-8.6)$, lived alone $\left(116 \quad(46 \%) \quad v . \quad 55 \quad(22 \%), \quad \chi^{2}=33.1\right.$, d.f. $=1, \quad P<0.001, \quad$ OR $=3.1, \quad 95 \% \quad$ CI 2.1-4.5) and were unemployed (225 $(90 \%)$ v. $76(30 \%), \chi^{2}=187.4$, d.f. $=1$, $P<0.001, \mathrm{OR}=21.5,95 \%$ CI 13-35.4).

\section{Use of drugs}

Taking all patients into account, $22(7 \%)$ reported problem use of drugs in the past year (5 problem use with opiates and 13 with cannabis), and $66(21 \%)$ at some time before then. Those who had problem use over the past year were more often male (19 $(10 \%)$ v. $3(3 \%), \chi^{2}=5.8$, d.f. $=1$,
$P=0.02, \quad$ OR $=4.1, \quad 95 \% \quad$ CI $1.2-14.3$ ), younger (mean age 34 years (s.d. 6 years) $v$. 46 years (s.d. 14); $t$-test: $t=3.9$, d.f. $=314, P<0.001 ; 95 \%$ CI for difference between means 6.1-18.7) and lived in more deprived areas (most deprived: $12(55 \%) v$. 53 (18\%): $\chi^{2}=16.5$, d.f. $=2, P<0.0001$, $\mathrm{OR}=5.4,95 \%$ CI 2.2-13.1).

Significantly more patients than controls reported harmful use, dependence or problem use of drugs, both in the past year and at some time before (Table 2).

Of 316 patients rated by key informants, 26 (9\%) had current misuse, dependence, or severe dependence on drugs. Through the SCAN, 14 of these 26 were rated as having problem use of drugs over the past year. Of 56 urine samples tested for cannabis, one was positive, a patient who had reported recent use. Of 40 hair samples tested, 7 (18\%) yielded positive results for any drug $(5$

Table I Social, demographic and clinical data in patients and controls

\begin{tabular}{|c|c|c|}
\hline & Patients $(n=316)$ & Controls $(n=250)$ \\
\hline \multicolumn{3}{|l|}{ Gender, $n$ (\%) } \\
\hline Male & $197(62)$ & $154(61)$ \\
\hline Female & $119(38)$ & $97(39)$ \\
\hline Age, years (s.d.) & $45(14)$ & $45(13)$ \\
\hline \multicolumn{3}{|l|}{ Deprivation category,' n (\%) } \\
\hline Most affluent & $56(19)$ & $40(16)$ \\
\hline Middle & $172(60)$ & $161(66)$ \\
\hline Most deprived & $60(21)$ & $43(18)$ \\
\hline \multicolumn{3}{|l|}{ Marital status, $n$ (\%) } \\
\hline Single & $214(68)$ & $60(24)$ \\
\hline Married/partner & $47(15)$ & $152(61)$ \\
\hline Divorced/separated & $45(14)$ & $30(12)$ \\
\hline Widowed & $10(3)$ & $9(3)$ \\
\hline \multicolumn{3}{|l|}{ Domiciliary status, $n$ (\%) } \\
\hline Parents & $45(14)$ & $23(9)$ \\
\hline Spouse/children & $54(17)$ & $161(64)$ \\
\hline With friends & $9(3)$ & $5(2)$ \\
\hline Alone & $14 \mid(45)$ & $55(22)$ \\
\hline Other & $67(2 I)$ & 7 (3) \\
\hline \multicolumn{3}{|l|}{ Employment status, $n(\%)$} \\
\hline Paid employment & $25(8)$ & $175(70)$ \\
\hline Not employed & $290(92)$ & $76(30)$ \\
\hline Length of illness, ${ }^{2}$ years (s.d.) & $18(13)$ & - \\
\hline $\begin{array}{l}\text { Number (\%) with OPCRIT-derived } \\
\text { ICD-I0 diagnosis of schizophrenia }\end{array}$ & $269(85)$ & - \\
\hline $\begin{array}{l}\text { Number (\%) with OPCRIT-derived } \\
\text { DSM-IV diagnosis of schizophrenia }\end{array}$ & $250(80)$ & - \\
\hline
\end{tabular}

I. Carstairs deprivation index (Carstairs \& Morris, 1991).

2. As estimated from first appearance of psychotic symptoms. 
for opiates, 1 patient and 4 controls). The patient and one control had reported recent use. One patient and one control tested positive for sedatives, and although neither reported use, the patient had received a prescribed sedative. One control tested positive for stimulants and had not reported use.

\section{Use of alcohol}

Taking all patients into account, 49 (16\%) reported problem use of alcohol in the past year and $122(39 \%)$ at sometime before then. Those who had problem use of alcohol over the past year were more often male $\left(39(20 \%) v .10(8 \%), \chi^{2}=7.4\right.$, d.f. $=1$, $P=0.006$, OR $=2.7,95 \%$ CI 1.3-5.6), and younger (mean age 39 years (s.d. 10) $v$. 46 years (s.d. 14); $t$-test: $t=3.4$, d.f. $=314$, $P=0.001,95 \%$ CI for difference between means 3.1-11.5). Significantly more patients than controls reported harmful use, dependence or problem use of alcohol in the past year and dependency at some time previously (Table 3 ).

When rated by key informants, 41 $(15 \%)$ of 316 patients had current misuse, dependence or severe dependence on alcohol. Through the SCAN, 22 of these 41 were rated as having problem use of alcohol over the past year.

\section{Alcohol and/or drug use}

More patients than controls had problems with alcohol or drugs in the past year (64 $(20 \%)$ v. $30 \quad(12 \%) ; \quad \chi^{2}=6.9, \quad$ d.f. $=1$, $P=0.008, O R=1.9,95 \%$ CI $1.2-2.9$ ), but not at some time previously. Seven patients and one control had problems with both drug and alcohol use in the past year.

\section{Use of tobacco}

Taking all patients into account, 205 (65\%) were current smokers. More male than female patients were current smokers (141 $(72 \%)$ v. $64 \quad(54 \%), \chi^{2}=10.1, \quad$ d.f. $=1$, $P=0.002, \mathrm{OR}=2.2,95 \%$ CI $1.3-3.5)$ and current smokers were younger (mean age 43 years (s.d. 13) v. 49 years (s.d. 16); $t$-test: $t=3.3$, d.f. $=314, P=0.001,95 \%$ CI for difference between means 2.4-9.1).

Significantly more patients than controls were current smokers (162 (65\%) v. $99(40 \%), \chi^{2}=33.0$, d.f. $=1, P<0.001$, $\mathrm{OR}=2.9,95 \%$ CI $1.9-4.1$ ), and of those who smoked cigarettes as opposed to 'roll-ups', more patients were heavy smokers (20 or more cigarettes/day; Table 4)
Table 2 Drug use

\begin{tabular}{lcccc}
\hline & $\begin{array}{c}\text { Patients } \\
(n=250) \\
n(\%)\end{array}$ & $\begin{array}{c}\text { Controls } \\
(n=250) \\
n(\%)\end{array}$ & $\begin{array}{c}\text { Chi-squared } \\
P\end{array}$ & $\begin{array}{c}\text { Case/control OR } \\
(95 \% \mathrm{Cl})\end{array}$ \\
& & & & \\
\hline $\begin{array}{l}\text { Past year } \\
\text { Harmful use }\end{array}$ & $17(7)$ & $5(2)$ & 0.013 & $4.0(1.3-11.9)$ \\
Dependence & $14(6)$ & $2(1)$ & 0.010 & $7.0(1.6-30.8)$ \\
Problem use & $18(7)$ & $5(2)$ & 0.009 & $4.2(1.4-12.6)$ \\
At any time before past year & & & & \\
Harmful use & $48(19)$ & $14(6)$ & $<0.001$ & $5.2(2.5-11.2)$ \\
Dependence & $38(15)$ & $9(4)$ & $<0.001$ & $5.1(2.3-11.6)$ \\
Problem use & $50(20)$ & $15(6)$ & $<0.001$ & $4.9(2.4-10.0)$ \\
\hline
\end{tabular}

Table 3 Alcohol use

\begin{tabular}{lcccc}
\hline & $\begin{array}{c}\text { Patients } \\
(n=250) \\
n(\%)\end{array}$ & $\begin{array}{c}\text { Controls } \\
(n=250) \\
n(\%)\end{array}$ & $\begin{array}{c}\text { Chi-squared } \\
P\end{array}$ & $\begin{array}{c}\text { Case/control OR } \\
(95 \% \mathrm{Cl})\end{array}$ \\
& & & & \\
\hline $\begin{array}{l}\text { Past year } \\
\quad \text { Harmful use }\end{array}$ & $41(16)$ & $23(9)$ & 0.016 & $2.0(1.1-3.5)$ \\
$\quad$ Dependence & $17(7)$ & $7(3)$ & 0.040 & $2.7(1.00-6.8)$ \\
$\quad$ Problem use & $42(17)$ & $25(10)$ & 0.027 & $1.8(1.1-3.2)$ \\
At any time before past year & & & & \\
$\quad$ Harmful use & $97(39)$ & $84(34)$ & 0.206 & $1.3(0.9-1.9)$ \\
$\quad$ Dependence & $47(19)$ & $21(8)$ & 0.001 & $2.6(1.5-4.7)$ \\
Problem use & $99(40)$ & $84(34)$ & 0.145 & $1.3(0.9-1.9)$ \\
\hline
\end{tabular}

Table 4 Tobacco use

\begin{tabular}{lcc}
\hline & Patients $(n=250)$ & Controls $(n=250)$ \\
\hline Smoking status, $n$ (\%) & $162(65)^{1}$ & \\
$\quad$ Current smoker & $34(14)$ & $99(40)^{\prime}$ \\
Ex-smoker & $196(79)$ & $62(25)$ \\
Ever smoked & $52(21)$ & $161(65)$ \\
Never smoked & $(n=125)$ & $89(36)$ \\
Number of cigarettes smoked per day, ${ }^{2} n(\%)$ & $1(1)$ & $(n=82)$ \\
$<1$ & $8(6)$ & $3(4)$ \\
$1-9$ & $21(17)$ & $16(20)$ \\
$10-19$ & $45(36)$ & $25(30)$ \\
$20-29$ & $20(16)$ & $30(36)$ \\
$30-39$ & $30(24)$ & $3(4)$ \\
$\geqslant 40$ & & $5(6)$ \\
\hline
\end{tabular}

I. $\chi^{2}=33.0$, d.f. $=I, P<0.001$.

2. Excludes 'roll-ups'. 
(95 (76\%) v. $38(46 \%), \chi^{2}=18.9$, d.f. $=1$, $P<0.001, \mathrm{OR}=3.7,95 \%$ CI $2.0-6.7)$.

\section{Multivariate analysis}

Conditional logistic regression, comparing patients with controls, was carried out using the following factors: site (Nithsdale, Glasgow, Aberdeen), current smoking, problem with drugs and problem with alcohol. The analysis was carried out for problems both in the past year and at any time before that. Numbers of current smokers were significantly different in both analyses $(P<0.001$ in both cases), as were numbers with problems with drugs $(P=0.04, P<0.001)$. Although there were no differences in numbers having problems with alcohol, further analyses examining harmful use and dependence found that more patients had harmful use in the past year $(P=0.04)$ and dependence at some time previously $(P=0.03)$.

\section{DISCUSSION}

In this study 316 of 446 people with schizophrenia and 250 controls identified in three different settings in Scotland were interviewed to elicit the extent of their alcohol, drug and tobacco use. The most striking difference between patients and controls was in tobacco consumption. Although there were statistically significant differences between patients and controls in the numbers who had problem use of drugs and alcohol, the number of patients was small, especially for drugs.

\section{Methodological issues \\ Identification of patients}

With regard to identification of patients, it was probably more comprehensive in Nithsdale than in Glasgow and Aberdeen as there has been over 20 years' experience in that area in identifying patients by the key informant method. This is reflected in similar prevalence rates in the three areas; the prevalence of schizophrenia is probably less in a rural area (Torrey \& Bowler, 1990).

\section{Identification of controls}

The identification of control subjects was slightly different in the three areas. Although in all three centres controls were obtained through GPs' patient lists, in Nithsdale and Glasgow it was through a national database, but in Aberdeen it was through a search of patient records in GPs' surgeries.

Not all patients identified were interviewed. It is possible that more of the patients identified but not interviewed had drug or alcohol problems. Yet, the distribution of the demographic factors associated with problem use (age and gender) was the same in those interviewed and not interviewed. It is also possible that patients and controls underreported their use. Hair and urine analysis, albeit in a small number of people, did not identify recent use of any non-prescribed drug in any patient who denied it; in contrast, four controls tested positive and had not reported use.

On SCAN interview patients reported alcohol and drug problems which key workers failed to identify, and vice versa. Although we cannot be certain, we believe that a detailed interview lasting 1-2 hours by a research nurse will give more accurate information than a brief interview with a keyworker. In previous reports, one found that keyworkers overestimated and the other found they underestimated drug misuse (Menezes et al, 1996; Brown, 1998).

\section{Comparison with other studies}

Problem use of drugs over the previous year $(7 \%)$ was a little lower than in a 6-month prevalence study of community patients in a rehabilitation service in Southampton, UK (Brown, 1998), where 10\% reported misuse of illicit drugs and $15 \%$ misuse of prescribed drugs over the previous 6 months, and in patients with psychosis in a community in south London (Menezes et al, 1996), where $11 \%$ reported misuse in the previous year. In both these urbanbased studies, however, patients were considerably younger. In both these studies and ours, a younger age was associated with more drug misuse.

The number of patients reporting problem use of alcohol in the past year $(16 \%)$ is similar to that in Southampton $(18 \%$; Brown, 1998) but lower than in south London (32\%; Menezes et al, 1996). However, the latter study contained patients with depressive psychosis, of whom twothirds had a problem with alcohol. Problem use at some time previous to the year before assessment in our study (39\%) was higher than lifetime problem use in a community sample of patients with schizophrenia in inner London (Duke et al, 1994).

Although absolute numbers were small, more people with schizophrenia than control subjects had problems with drugs both in the past year or at some time previously and, with regard to alcohol, harmful use in the past year or dependence at some time previously. What leads more people with schizophrenia to substance misuse has been discussed extensively (Siegfried, 1998; Blanchard et al, 2000). They may misuse drugs for the same reasons as the rest of the population (to relax, increased availability, increased acceptability). Drugs might be used to 'self-medicate' symptoms of illness or drug side-effects. Finally, genetic factors could lead to both drug misuse and schizophrenia. We would like to emphasise, however, that in our study $93 \%$ and $84 \%$ of patients respectively did not have problem use of drugs or alcohol in the previous year.

\section{Tobacco}

Use of alcohol or drugs in our patients was greatly overshadowed by use of tobacco. Almost two-thirds of our patients were current smokers, and most who smoked were heavy smokers. These findings are similar to a recent survey of smoking in south-west Scotland (Kelly \& McCreadie, 1999), but it is a somewhat lower rate than that found in a widely quoted American study (Hughes et al, 1986), where $88 \%$ of out-patients with schizophrenia were smokers. A future paper (further details available from the author upon request) will examine service use by those who do and do not have current problem use of drugs or alcohol, and discuss the need, or otherwise, for dual diagnosis clinics. However, in our view the most important dual diagnosis is schizophrenia and tobacco use. Patients with schizophrenia die early, especially from smoking-related diseases (Brown et al, 2000). Attempts to help people with schizophrenia give up smoking should be a top priority.

\section{ACKNOWLEDGEMENTS}

Members of the Scottish Comorbidity Study Group: Crichton Royal Hospital, Dumfries: R. McCreadie, V. Sharkey, J. Halliday, S. Macdonald, T. MacEwan, S. Farrington. Gartnavel Royal Hospital, Glasgow: R. Cantwell, C. Kelly, A. Burns, M. Smith, C. Melville, J.White. Royal Cornhill Hospital, Aberdeen: J. Eagles, P. Sclare, P. Gordon, A. Lawrie. Health Services Research Unit, University of Aberdeen: S. Naji, J. Gibb, J. Andrew. 


\section{REFERENCES}

American Psychiatric Association (1994) Diagnostic and Statistical Manual of Mental Disorders (4th edn). Washington, DC: APA

Bernadt, M.W. \& Murray, R. M. (1986) Psychiatric disorder, drinking and alcoholism: what are the links? British Journal of Psychiatry, 148, 393-400.

Blanchard, J. J., Brown, S. A., Horan, W., et al (2000) Substance use disorders in schizophrenia: review, integration and a proposed model. Clinical Psychology Review, 20, 207-234.

Brown, S. (1998) Substance misuse in a chronic psychosis population. Psychiatric Bulletin, 22, 595-598.

_ , Barraclough, B. \& Inskip, H. (2000) Causes of the excess mortality of schizophrenia. British Journal of Psychiatry, 177, 212-217.

Carstairs, V. \& Morris, R. (1991) Deprivation and Health in Scotland. Aberdeen: Aberdeen University Press.

Drake, R. E. Osher, F. C. \& Wallach, M. A. (1989) Alcohol use and abuse in schizophrenia. Journal of Nervous and Mental Disease, 177, 408-414.

Duke, P. J., Pantelis, C. \& Barnes, T. R. E. (1994) South Westminster schizophrenia survey. Alcohol use and its relationship to symptoms, tardive dyskinesia and illness onset. British Journal of Psychiatry, 164, 630-636.

Hughes, J. R., Hatsukami, D. K., Mitchell, J. E., et al (1986) Prevalence of smoking among psychiatric outpatients. American Journal of Psychiatry, 143, 993-997.

Kelly, C. \& McCreadie, R. G. (1999) Smoking habits, current symptoms and premorbid characteristics of schizophrenic patients in Nithsdale, Scotland. American Journal of Psychiatry, 156, 175I-1757.

McCreadie, R. G. (1982) The Nithsdale schizophrenia survey: I. Psychiatric and social handicaps. British Journal of Psychiatry, 140, 582-586.

McGuffin, P., Farmer, A. \& Harvey, I. (199I) A polydiagnostic application of operational criteria in studies of psychotic illness. Archives of General Psychiatry, 48, 764-770.

Menezes, P. R., Johnson, S., Thornicroft, G., et al (1996) Drug and alcohol problems among individuals with severe mental illness in south London. British Journal of Psychiatry, 168, 612-619.

Regier, D. A., Farmer, M. E., Rae, D. S., et al (1990) Comorbidity of mental disorders with alcohol and other

\section{CLINICAL IMPLICATIONS}

- Problem use of alcohol and drugs in people with schizophrenia is greater than in members of the general population, but absolute numbers are small.

- A total of $93 \%$ and $84 \%$ of patients, respectively, did not have problem use of drugs or alcohol in the previous year.

- Almost two-thirds of patients were smokers; this is by far and away the most important dual diagnosis in schizophrenia.

\section{LIMITATIONS}

- Success in identifying patients was probably greater in the rural than in the urban or suburban areas.

- Detailed interviews of subjects by a research nurse and brief interviews by keyworkers produced conflicting results.

- In a small sample of controls who did not report drug use, hair analysis suggested otherwise.

ROBIN G. McCREADIE, DSc, Department of Clinical Research, Crichton Royal Hospital,

Dumfries DGl 4TG, UK. Tel: +44 (0) 1387 244000; fax: 44 (0) 1387257735 ;

e-mail: rgmccreadie_crh@compuserve.com

(First received 30 November 200I, final revision 7 May 2002, accepted 29 May 2002)

drug abuse: results from the epidemiological catchment area (ECA) study. JAMA, 264, 25II-25I8.

Scottish Office (1997) A Framework for Mental Health Services in Scotland. Edinburgh: The Scottish Office.

Siegfried, N. (1998) A review of comorbidity: major mental illness and problematic substance use. Australia and New Zealand Journal of Psychiatry, 24, 707-717.

Torrey, E. F. \& Bowler, A. (1990) Geographical distribution of insanity in America: evidence for an urban factor. Schizophrenia Bulletin, 16, 591-604.
Waldron, G., Chalmers, J., Bone, A., et al (1995) Health and Lifestyles in Dumfries \& Galloway in 1995 Dumfries: Dumfries \& Galloway Health Board.

World Health Organization (1992) The ICD-10 Classification of Mental and Behavioural Disorders. Geneva: WHO.

- (1994) Schedules for Clinical Assessment in Neuropsychiatry. Version 2. Geneva: WHO. 